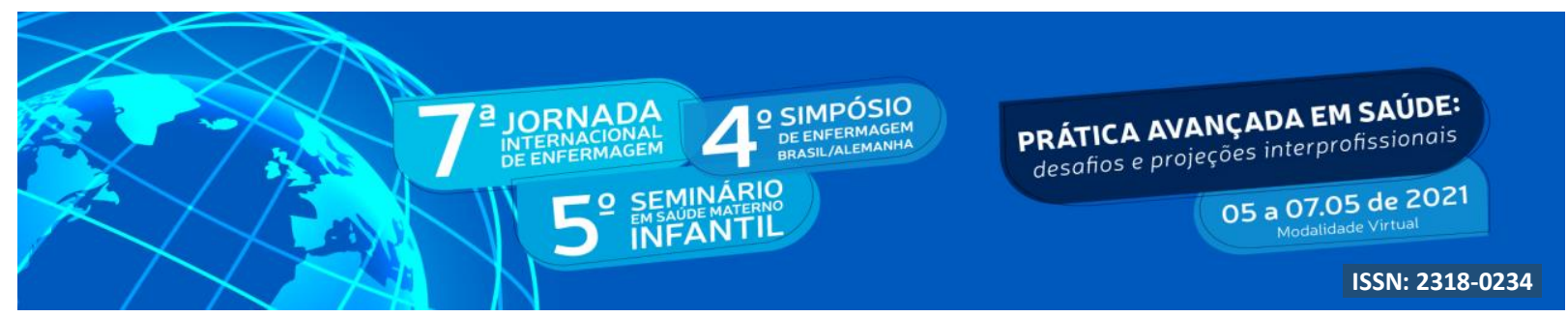

DOI: http://doi.org/10.48195/jie2021-116

\title{
COMPLICAÇÕES PROVOCADAS PELA COVID-19 DURANTE A GRAVIDEZ: REVISÃO INTEGRATIVA
}

\section{Graziele Alves Flores'; Pabline Pivetta de Oliveira² ${ }^{2}$ Dielli Arend Teixeira ${ }^{3}$; Maclaine de Oliveira Roos ${ }^{4}$; Rosane Gomes de Oliveira ${ }^{5}$; Regina Gema Santini Costenaro ${ }^{6}$}

\begin{abstract}
RESUMO
Objetivou-se analisar e descrever as complicações provocadas pela Covid-19 durante a gestação presentes na literatura nacional e internacional. Realizou-se o levantamento bibliográfico nas bases de dados: PubMed, Scientific Eletronic Library Online (SCIELO) e Biblioteca Virtual em Saúde (BVS). Os estudos alcançados foram analisados resultando na principal questão em xeque: Complicações causadas pela Covid-19 durante a gravidez. Diante da pesquisa verificou-se que a COVID-19 está gerando diversas complicações durante a gravidez, essas que podem ter efeitos psicológicos de curto e longo prazo, ademais a escazes de evidencias acerca da forma de transmissão mãe-bebê, parto seguro, formas de prevenção ainda não são questões conclusivas. Diante disso busca-se levar informações, sanar dúvidas e oferecer apoio no planejamento dos atendimentos as gestantes frente ao atual cenário.
\end{abstract}

Palavras-chave: Gravidez; Infecções por coronavírus; Enfermagem.

\begin{abstract}
The objective of this study was to analyze and describe the complications caused by Covid-19 duringpregnancy present in the national and international literature. The bibliographic survey was carried out in the databases: PubMed, Scientific Electronic Library Online (SCIELO) and Virtual Health Library (BVS). The studies obtained were analyzed resulting in the main question in question: Complications caused by Covid-19 during pregnancy. In view of the research, it was found that COVID-19 is generating several complications during pregnancy, these that may have short- and longterm psychological effects, in addition to the scarcity of evidence about the form of mother-baby transmission, safe delivery, forms of prevention are not yet conclusive issues. In view of this, it is sought to bring information, to answer doubts and offer support in the planning of care to pregnant women in the face of the current scenario.
\end{abstract}

Key Words: Pregnancy; Coronavirus infections; Nursing.

\footnotetext{
${ }^{1}$ Estudante do Curso de Enfermagem. Bolsista FAPERGS. Universidade Franciscana. E-mail: flores.graziele8@gmail.com

${ }^{2}$ Estudante do Curso de Enfermagem. Bolsista PROBIC. Universidade Franciscana. E-mail: pablinepivetta@gmail.com

${ }^{3}$ Estudante do Curso de Enfermagem. Universidade Franciscana. E-mail: dielliarend@gmail.com

${ }^{4}$ Médica pediatra. Aluna do mestrado profissional em saúde materna e infantil. Universidade Franciscana. UFN. E-mail: maclaine-ross@ @aude.rs.gov.br

${ }^{5}$ Enfermeira. Aluna do mestrado profissional em saúde materna e infantil. Universidade Franciscana. UFN. Email: rosane.oliveira@ufn.edu.br

${ }^{6}$ Orientador. Enfermeira. Doutora. Docente do curso de Enfermagem e no mestrado profissional em saúde materna e infantil - Universidade Franciscana. E-mail: reginacostenaro@gmail.com
} 


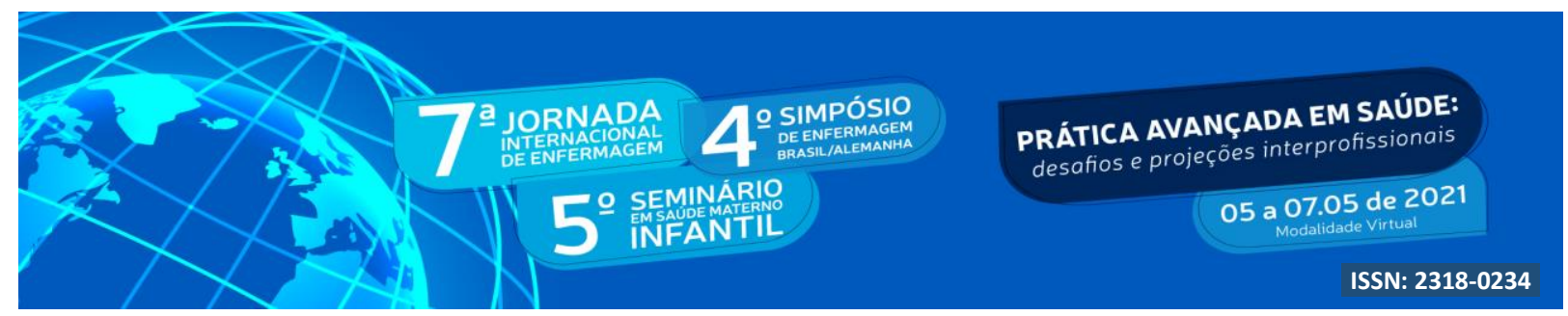

\section{INTRODUÇÃO}

No final de dezembro de 2019, a Organização Mundial da Saúde (OMS) foi notificada de um conjunto de casos de pneumonia de etiologia desconhecida na cidade de Wuhan, (China). Mais de cinco meses depois, a doença pelo Coronavírus (COVID-19), como foi posteriormente nomeada, já chegou a 188 países/regiões, de acordo com a Universidade Johns Hopkins (JHU), nos quais já é responsável por centenas de milhares de mortes. Declarada como pandemia, em março de 2019, a COVID-19 é causada pelo coronavírus 2 relacionado à síndrome respiratória aguda grave (SARS-CoV-2) também conhecido como "novo coronavírus", um vírus que, de acordo com o Centro de Controle e Prevenção de Doenças (CDC), se espalha facilmente e de maneira sustentada entre as pessoas (SOUTO, 2020).

A mortalidade do coronavírus emergente de 2019 está relacionada à síndrome do desconforto respiratório, à comorbidades e falência dos múltiplos órgãos que levam ao óbito. O quadro clínico em humanos infectados varia de leve (nulo ou menor) a sinais e sintomas graves, incluindo a morte. Sendo que as infecções assintomáticas a leves podem não ser percebidas e pode haver a não conversão ou reatividade cruzada em casos confirmados de reação em cadeia pela polimerase (PCR) de ácido nucleico, exigindo, mais estudos de soro vigilância para compreender a resposta de anticorpos frente a infecção pelo SARS-CoV-2 (OLIVEIRA; CASTRO; COSTA, 2021).

Em 2011, foi lançada a "Rede Cegonha" que propõe a melhoria do atendimento às mulheres durante a gravidez, o parto, o pós-parto, ao recém-nascido e às crianças até 2 (dois) anos de idade. Nesse sentido, a Rede Cegonha assegura que o período gravídico-puerperal seja acessível por meio de atendimentos seguros, humanizados e de qualidade (BRASIL, 2017). Mulheres grávidas são mais suscetíveis a patógenos respiratórios e pneumonia grave, porque estão em estado imunossupressor e alterações fisiológicas adaptativas durante a gravidez. Todas as idades podem ser susceptíveis a contaminação com o novo coronavírus. Sendo que o indivíduo infectado pode espalhar o vírus enquanto estiver sentindo os sintomas, em período de latência ou até mesmo em recuperação clínica (CHEN, et al.,2020).

A literatura aponta que gestantes com infecção por Sars-Cov-2 e que evoluem para um 


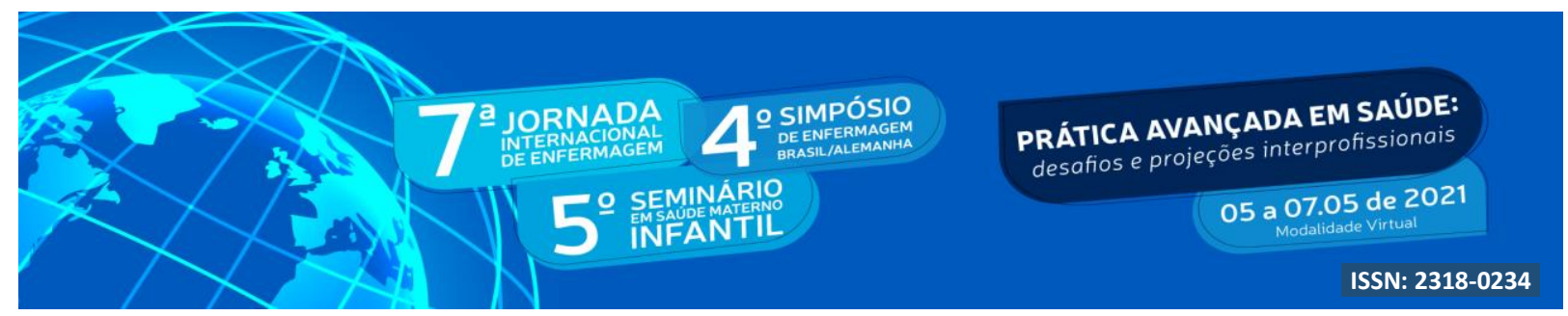

quadro grave associado a uma comorbidade têm probabilidade aumentada de passar por um parto cesariano de emergência ou um parto prematuro, o que eleva o risco de morte materna e neonatal. Mesmo diante de um cenário adverso, os direitos das gestantes devem ser respeitados, mas algumas maternidades e hospitais, como forma de prevenir a Covid-19, têm adotado o isolamento no momento do parto. Esta medida diz respeito à não permissão de um acompanhante antes, durante e após o parto, direito esse apoiado na Lei $\mathrm{n}^{\mathrm{o}}$ 11.108/2005, conhecida como Lei do Acompanhante (ESTRELA et al., 2020).

A gestante possui liberdade de escolher alguém, seja marido, companheiro, familiar ou pessoa próxima a ela, para acompanhá-la no momento do parto. Não é exigido preparo técnico anterior, para ser este acompanhante, pois este se limita a ser alguem com quem a gestante possa socializar suas angustias, seus medos, e assim poderá minimizar sua ansiedade e encorajar a parturiente no enfrentamento das dificuldades que são inerentes ao momento do trabalho de parto e parto (SOUZA; GUALDA, 2016, p. 2).

O Ministério da Saúde, através do Manual de Recomendações para a Assistência à Gestante e Puérpera frente à Pandemia de COVID-19, publicou uma série de recomendações. As consultas de pré-natal deverão seguir as mesmas normas da população em geral e o prénatal de todas as gestantes deverá ser assegurado. Orienta-se que, se necessário, os exames e ultrassonografias possam ser realizados no mesmo dia da consulta presencial (BRASIL, 2020). Diante do exposto, questiona-se quais as complicações provocadas pela Covid-19 durante a gravidez evidenciadas na literatura nacional e internacional?

\section{OBJETIVO}

Objetivou-se estudar, discutir e descrever as complicações provocadas pela Covid-19 durante a gestação presentes na literatura nacional e internacional.

\section{METODOLOGIA}

Trata-se de uma revisão integrativa da qual determina o conhecimento atual sobre uma temática específica, já que é conduzida de modo a identificar, analisar e sintetizar resultados 


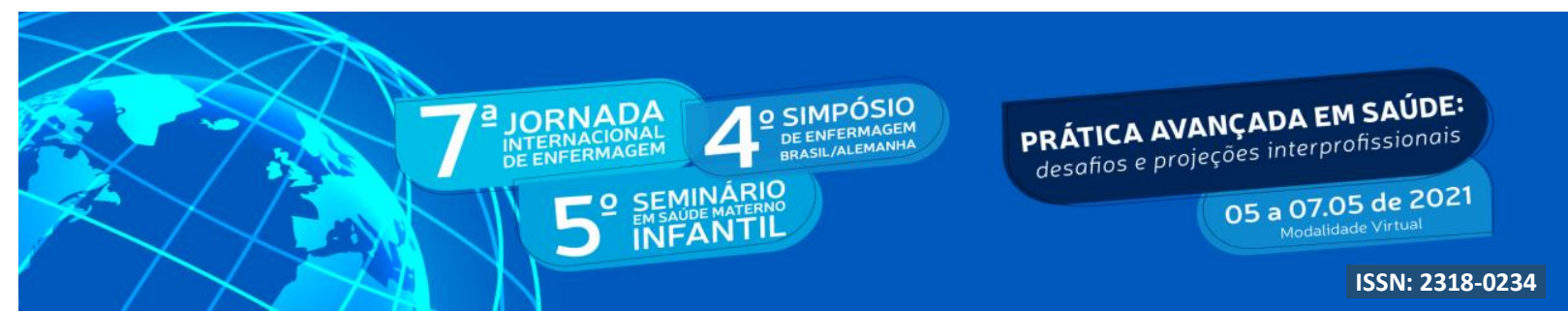

de estudos independentes sobre o mesmo assunto, contribuindo, pois, para uma possível repercussão benéfica na qualidade dos cuidados prestados ao paciente. Pontua-se, então, que o impacto da utilização da revisão integrativa se dá não somente pelo desenvolvimento de políticas, protocolos e procedimentos, mas também no pensamento crítico que a prática diária necessita (SOUZA; SILVA; CARVALHO, 2010).

A revisão integrativa foi norteada pela seguinte questão: Quais são as complicações provocadas pela Covid-19 durante a gravidez e puerpério? Para obtermos a resposta da questão proposta, a seleção dos artigos, realizada no mês de março de 2021, foi conduzida a partir de três bases de dados: PubMed, Scientific Eletronic Library Online (SCIELO) e Biblioteca Virtual em Saúde (BVS). Os descritores aplicados, de acordo com as definições do DECS - Descritores em Ciências da Saúde foram: Gravidez, Infecção por Coronavírus; Enfermagem, sendo estas empregadas na língua portuguesa.

Os critérios de inclusão dos artigos para este estudo foram determinados a partir de pesquisas publicadas internacionalmente, a partir do ano de 2019. Foi definido como critérios de exclusão: artigos que não atendessem a temática proposta e a indagação do estudo, revisões de literatura, teses e dissertações. Destaca-se que não houve recorte temporal para que houvesse mais publicações sobre a temática.

Realizaram-se dois mecanismos de busca nas bases de dados descritas acima. Na base de dados PubMed, associaram-se os descritores "Gravidez", "Infecção por Coronavírus" e "Enfermagem" com o operador booleano “and". Essa demanda resultou em nenhum (0) estudo. Na base de dados da SCIELO foi utilizada a mesma estratégia de busca cujo resultou em dois (2) estudos, sendo que apenas um atendeu aos requisitos da proposta de estudo. $\mathrm{Na}$ terceira busca, sendo ela na BVS, ainda utilizando a mesma estratégia, surgiram vinte e um (21) artigos, sendo estes foram filtrados originando um total de vinte (20) artigos.

Para a seleção dos artigos foi realizada a leitura dos títulos e dos resumos e, caso necessário, a leitura na íntegra, seguindo os critérios de inclusão e exclusão. Esse processo resultou na inclusão de dez (10) publicações, as quais compuseram o corpus deste estudo, sendo um da SCIELO e nove (09) da BVS. 


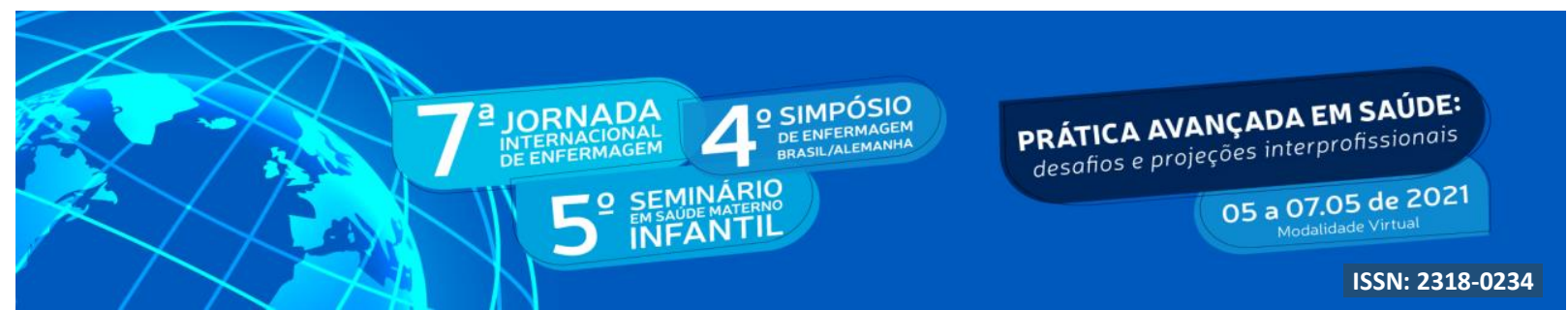

\section{RESULTADOS E DISCUSSÃO}

Para apresentação dos resultados desenvolveu-se um quadro sinóptico, no qual estão os artigos inseridos na revisão integrativa. As subcategorias analisadas foram código, título, ano de publicação/ periódico e delineamento da pesquisa, conforme descrito na quadro 1.

Quadro 1 - Referente aos estudos incluídos na Pesquisa

\begin{tabular}{|c|c|c|c|}
\hline Código & Título & $\begin{array}{l}\text { Periódico/ } \\
\text { Ano }\end{array}$ & $\begin{array}{c}\text { Delineamento } \\
\text { da pesquisa }\end{array}$ \\
\hline G1 & O medo do parto em tempo de pandemia do novo Coronavírus. & $\begin{array}{l}\text { SCIELO. } \\
2020\end{array}$ & $\begin{array}{l}\text { Análise } \\
\text { reflexiva }\end{array}$ \\
\hline G2 & $\begin{array}{l}\text { Atendimento de gestantes na atenção primária a saúde pela } \\
\text { enfermagem durante a pandemia do SARS-COV-2. }\end{array}$ & $\begin{array}{l}\text { BVS. } \\
2020 \\
\end{array}$ & Descritivo \\
\hline G3 & $\begin{array}{l}\text { A experiência psicológica de pacientes obstétricas e profissionais de } \\
\text { saúde após a implementação do teste universal SARS-CoV- } 2 \text {. }\end{array}$ & $\begin{array}{l}\text { BVS. } \\
2020\end{array}$ & Coorte \\
\hline G4 & $\begin{array}{l}\text { Promoção da saúde mental materno-infantil e cuidados informados } \\
\text { sobre o trauma durante a pandemia de COVID- } 19 \text {. }\end{array}$ & $\begin{array}{l}\text { BVS. } \\
2020\end{array}$ & $\begin{array}{l}\text { Comentário } \\
\text { crítico }\end{array}$ \\
\hline G5 & $\begin{array}{l}\text { O impacto da pandemia de coronavírus (COVID-19) na maternidade } \\
\text { na Europa. }\end{array}$ & $\begin{array}{l}\text { BVS. } \\
2020\end{array}$ & Editorial \\
\hline G6 & $\begin{array}{l}\text { Redesenho da assistência pré-natal: criando modelos flexíveis de } \\
\text { assistência à maternidade por meio da assistência virtual. }\end{array}$ & $\begin{array}{l}\text { BVS. } \\
2020\end{array}$ & Ponto de vista \\
\hline G7 & $\begin{array}{l}\text { Nova doença por vírus corona (COVID - 19) na gravidez: quais } \\
\text { recomendações clínicas devem ser seguidas? }\end{array}$ & $\begin{array}{l}\text { BVS. } \\
2020\end{array}$ & Editorial \\
\hline G8 & $\begin{array}{l}\text { Los derechos de las mujeres en el parto deben ser respetados durante } \\
\text { la pandemia de Coronavirus. }\end{array}$ & $\begin{array}{l}\text { BVS. } \\
2020\end{array}$ & Recomendação \\
\hline G9 & $\begin{array}{l}\text { Gestantes no contexto da pandemia da Covid-19: reflexões e } \\
\text { desafios. }\end{array}$ & $\begin{array}{l}\text { BVS. } \\
2020\end{array}$ & Comentário \\
\hline G10 & $\begin{array}{l}\text { Direitos humanos das mulheres no parto frente à pandemia de Covid- } \\
\text { 19: o que fazer da enfermagem obstétrica. }\end{array}$ & $\begin{array}{l}\text { BVS. } \\
2020\end{array}$ & $\begin{array}{c}\text { Comunicação } \\
\text { livre }\end{array}$ \\
\hline
\end{tabular}

Fonte: Autoras desta pesquisa.

\subsection{Complicações causadas pela Covid-19 durante a Gravidez}

A transmissão da COVID-19 pelo indivíduo infectado ocorre, principalmente, nos três primeiros dias após o início dos sintomas, embora a propagação possa ocorrer antes mesmo do aparecimento destes e em estágios posteriores da doença. Um prazo de cinco dias se estabelece entre a exposição ao vírus e o início dos sintomas (tempo de incubação), embora o intervalo possa variar de 2 a 14 dias. Os sintomas são diversos, mas entre os mais comuns pode-se destacar a falta de ar, a tosse seca e a febre (SOUTO, 2020). 


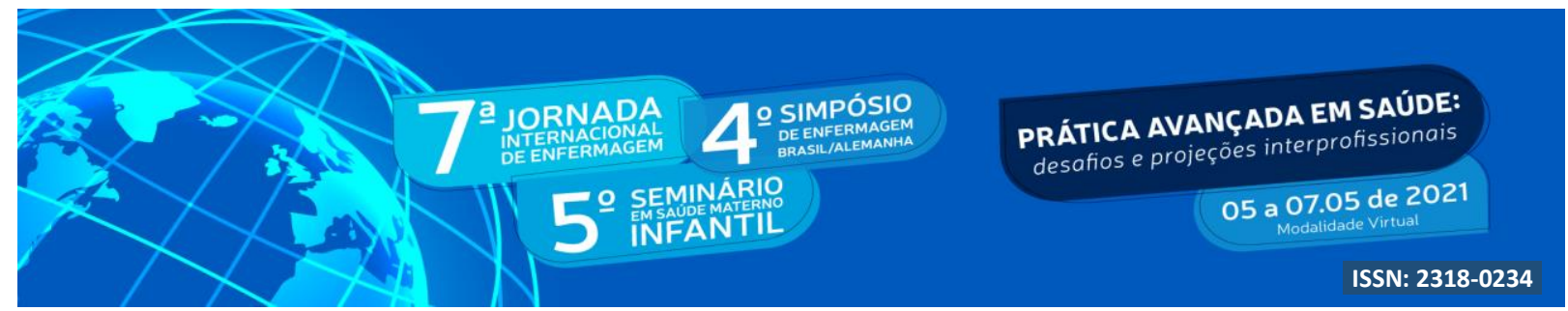

Observou-se com relação ao objetivo deste estudo, analisando as complicações causadas pela covid-19 durante a gestação na literatura internacional, que os estudos abordam de maneira expressiva o contágio de mulheres gestantes pelo coronavírus sendo que estas são consideradas um grupo clinicamente vulnerável comparadas a mulheres não gestantes (SOUTO; ALBUQUERQUE; PRATA, 2020). Os estudos G1, G2 G7 e G9 destacam que apesar de toda abordagem recente do cenário atual sobre o contágio do vírus da Covid-19, acerca da transmissão da mãe-bebê, ainda não são conclusivas.

As considerações de G2, G5 e G9 apontam que gestantes com infecção por Sars-Cov-2 e que evoluem para um quadro grave associado a uma comorbidade têm probabilidade aumentada de passar por um parto cesariano de emergência ou um parto prematuro, o que eleva o risco de morte materna e neonatal, ou ainda restrição de crescimento intrauterina, sofrimento fetal e aborto espontâneo, isto é, são questões destacadas da qual revelam desfechos negativos. Em contrapartida, G7 revela que não se sabe se o vírus aumenta o risco de aborto espontâneo e natimorto, porém especialistas expressam preocupações sobre a interrupção da gravidez por infecção congênita e teratogenicidade.

Tendo em vista esse cenário, muitas mulheres têm receio dos problemas que possam ocorrer durante o período da gestação e no momento do parto, como a possibilidade de transmissão vertical do vírus. Devido a todas essas informações e incertezas da ciência sobre os possíveis riscos de infecção, é compreensível o medo que as mulheres têm. Por isso, é importante que elas estejam atentas às fake News, devendo verificar se as notícias proveem de fontes confiáveis (ESTRELA et al., 2020). É indispensável destacar que devida as constantes mudanças que estão ocorrendo na rede de saúde, os estudos também redirecionam sobre um impacto negativo da Covid-19 às mulheres gestantes e puérperas no que diz respeito a sua saúde mental e psicológica.

Frente a esta questão G3 e G4 mencionam análises sobre a saúde mental e insegurança de mulheres grávidas, infectadas ou não pelo novo coronavírus. Ambos os estudos abordam sobre o potencial que a pandemia causa sobre danos de longo alcance, sendo que, durante a pandemia as mulheres correm maior riscos de depressão, ansiedade, transtorno de estresse pós-traumático e suicídio. Ademais, gestantes com teste positivo para SARS-CoV-2, possuem ainda uma experiencia negativa em ambiente hospitalar, relacionada a sua experiencia de 


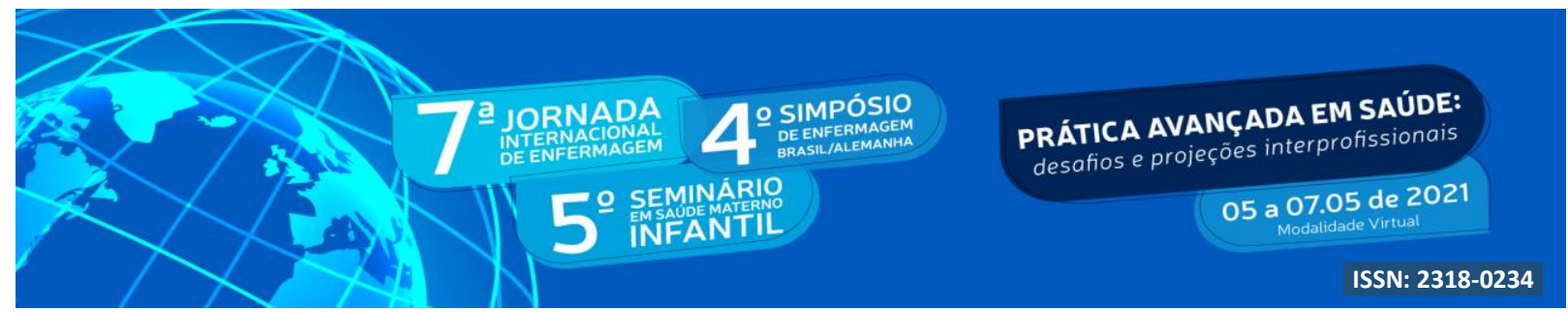

cuidado e separação do seu bebê, pois logo após o nascimento, algumas instituições adotam como precaução a separação de mãe e filho para evitar eventual contágio.

G3 evidência em sua pesquisa, acerca das experiencias negativas secundárias à percepção da separação neonatal após o nascimento do bebê e falta de apoio do provedor e do parceiro, uma vez que uma das medidas de precaução para o não contágio do vírus é o isolamento no momento do parto, não sendo permitido a presença de um acompanhante. G7 e G8 afirmam sobre a escassez de evidência no campo em que mulheres não possam dar à luz por via vaginal ou cesariana sendo mais segura em caso de suspeita ou confirmação de Covid19. O parto cirúrgico e o isolamento com separação do contato mãe-filho, sem amamentação, serão elegíveis para casos em que o quadro clínico da mãe ou da criança seja crítico (CARDOSO et al., 2021).

De modo geral sabe-se que o momento de dar à luz é significativamente único para a vida de cada mulher, cada uma possui seus anseios, seus desejos, seus sonhos e por este motivo todos devem ser respeitados independentemente do momento em que estamos vivenciando. O Brasil é o segundo país com maior taxa de cesarianas no mundo-57\% dos partos, e acredita-se que a atual pandemia possa aumentar ainda mais essa taxa, considerando os riscos da COVID-19 para os desfechos gestacionais (CARDOSO et al., 2021). Sendo assim G6, G8 e G9 conscientizam em suas relações que mesmo diante de um panorama adverso, o direito das gestantes deve ser respeitado, levando em consideração sua condição clínica.

Nesta perspectiva, os estudos analisados ressaltam acerca da ideação de estratégias frente a todas estas problemáticas atuais. De tal modo que G5 G6 e G7, G9 e G10 buscam afirmar sobre a reorganização do fluxo das redes em saúde, fazendo com que os atendimentos e acompanhamentos pré-natais se sucedam por meio de conexões virtuais, pensando na flexibilidade do suporte e desenvolvendo caminhos alternativos de atendimento personalizado. Os estudos G1, G2, G3 e G4 baseiam-se nas recomendações para os profissinais de saúde a par das evidências atuais, diante cenário de risco de infecção, visto que os enfermeiros estão em uma posição única para fornecer essas intervenções de saúde materna e infantil como membros da equipe de assistência perinatal (CHOI et al., 2020). 


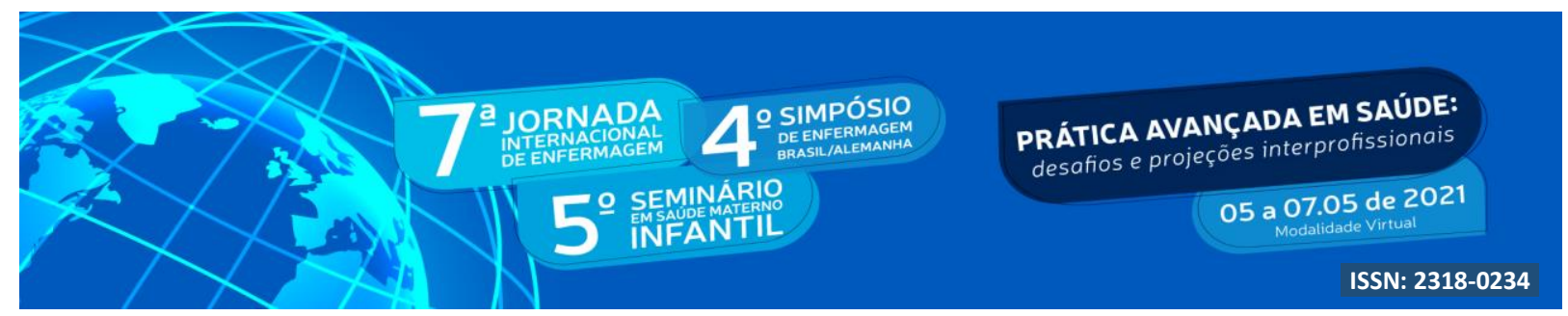

\section{CONCLUSÃO}

Vivenciar o período gestacional envolve muitos sentimentos, expectativas e inseguranças na gestante, assim é essencial que seja realizado o pré-natal de forma segura para evitar intercorrências. No entanto, com a pandemia do Coronavírus a realização do prénatal ficou prejudicada, uma vez que, as gestantes estão no grupo de risco, devido a encontrarem-se imunossuprimidas nesse período, assim tem maior possibilidade de serem infectadas. Além disso, os atendimentos foram redirecionados para os usuários que apresentaram os sintomas do novo vírus.

Nesse sentido, ficou evidente que a COVID-19 está gerando diversas complicações durante a gravidez, essas que podem ter efeitos psicológicos de curto e longo prazo, visto que, as gestantes estão desenvolvendo muitos sentimentos negativos como de medo, ansiedade, isolamento da família. Alem disso também estão associados o fato de não saber quais riscos esse vírus pode gerar na gravidez, falta de informações corretas e por não estar realizando presencialmente o acompanhamento de sua gestação. Apesar de o atendimento pré-natal estar sendo realizado por telefone ou vídeo chamada, as gestantes permanecem com receio de ter intercorrências e não serem visualizadas precocemente.

Diante disso, salienta-se que os profissionais de saúde devem estar em frequente comunicação com as gestantes com intuito de levar informações, sanar suas dúvidas, oferecer apoio emocional, planejar estratégias que possibilitem o vínculo materno-profissional assistindo essas gestantes conforme suas demandas e necessidades, visando passar mais segurança nessa fase complexa em que estão experienciando diante do atual cenário.

As limitações deste estudo reference ao fato da temática decorrer de uma circunstância recente no campo da pesquisa, por isso justifica-se a inclusão nos documentos avaliados de materiais editoriais e comentários.

\section{REFERÊNCIAS}

BENDER, W. R.; SRINIVAS, S.; COUTIFARIS, P.; ACKER, A.; HIRSHBERG, A. A experiência psicológica de pacientes obstétricas e profissionais de saúde após a implementação do teste universal SARS-CoV-2. American Journal of Perinatology, v.37, 


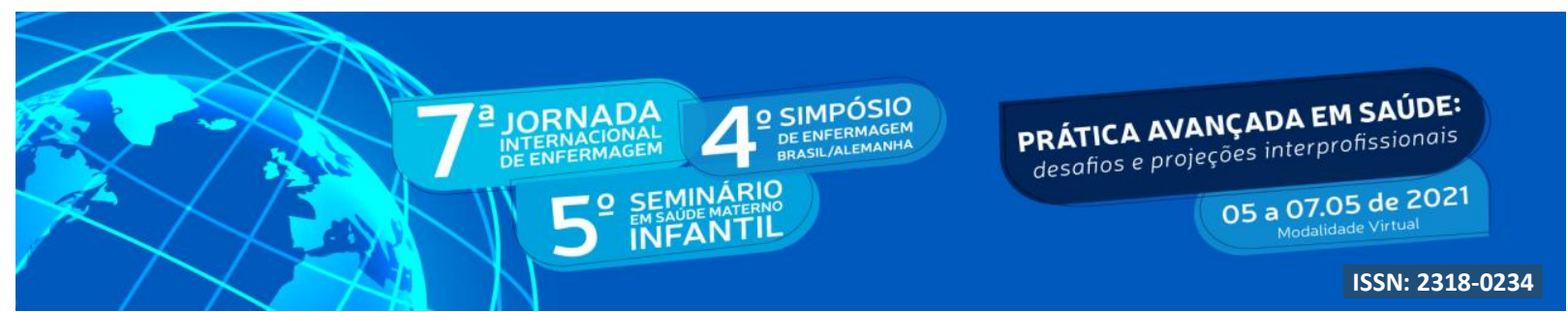

n.12, p.1271-1279, 2020.

BRASIL. Manual de Recomendações para a Assistência À Gestante e Puérpera frente à Pandemia de Covid-19. Secretaria de Atenção Primária à Saúde. Departamento de Ações Programáticas e Estratégicas Ministério da Saúde, 2020. Disponível em: $<$ http://189.28.128.100/dab/docs/portaldab/documentos/corona/manual_recomendacoes_gesta ntes_covid19.pdf $>$. Acesso em: 15 mar. 2021.

BRASIL. Ministério da Saúde. Rede Cegonha, 2017. Sobre o programa. Disponível em: $<$ https://www.saude.gov.br/acoes-e-programas/rede-cegonha/sobre-o-programa>. Acesso em: 11 mar. 2020.

CARDOSO, P. C. et al. A saúde materno-infatil no contexto da pandemia de COVID-19: evidencias, recomendações e desafios. Revista Brasileira de Saúde Materno Infantil, Recife, v. 21, n. 1, p. 213-220, fev./ 2021. Disponível em: <https://www.scielo.br/pdf/rbsmi/v21s1/pt_1519-3829-rbsmi-21-s1-0213.pdf>. Acesso em: 15 mar. 2021.

CHEN, H. et al. Características Clínicas e Transmissão Vertical intra uterina potencial de infecção por COVID-19 em nove mulheres grávidas: uma revisão retrospectiva de registros médicos. Lancet, China, v. 395, p. 809-815. mar./2020. Disponível em:

$<$ https://portaldeboaspraticas.iff.fiocruz.br/biblioteca/clinical-characteristics-and-intrauterinevertical-transmission-potential-of-covid-19-infection-in/>. Acesso em: 11 mar. 2021.

CHOI, K. R.; RECORDS, K.; LOW, L. K.; ALHUSEN, J.L.; KENNER, C.; BLOCH, J. R.; et al. Promoção da saúde mental materno-infantil e cuidados informados sobre o trauma durante a pandemia de COVID-19. Journal of obstetric, gynecology and neonatal nursing, v.49, n.5, p.409-415, 2020.

COXON, K.; TURIENZO, C. F.; KWEEKEL, L.; GOODARZI, B.; BRIGANTE, L.; SIMON, A.; et al. O impacto da pandemia de coronavírus (COVID-19) na maternidade na Europa. Midwifery, v.88, 2020.

ESTRELA, F. M. et al. Gestantes no contexto da pandemia da Covid-19: reflexões e desafios. Physis:Revista de Saúde Coletiva, Rio de Janeiro, v. 30, n. 2, p. 1-5, abr./2020. Disponível em: <https://www.scielo.br/pdf/physis/v30n2/0103-7331-physis-30-02-e300215.pdf>. Acesso em: 11 mar. 2021.

INTERNATIONAL CONFEDERATION OF MIDWIVES. Los derechos de las mujeres en el parto deben ser respetados durante la pandemia de Coronavirus. Netherlands; ICM; 2020. 4p.

HUAN, L.; GANESH, A. Nova doença por vírus corona (COVID - 19) na gravidez: quais recomendações clínicas devem ser seguidas? Acta Obstetricia et Gynecologica

Scandinavica, v.99, n.4, p.439-442, 2020.

MISQUITA, M.S.; SILVA, P. G.; BRAZ, G. A.; SOUSA, A.B.A.G.; MELO, D.F.C.; MELO, 


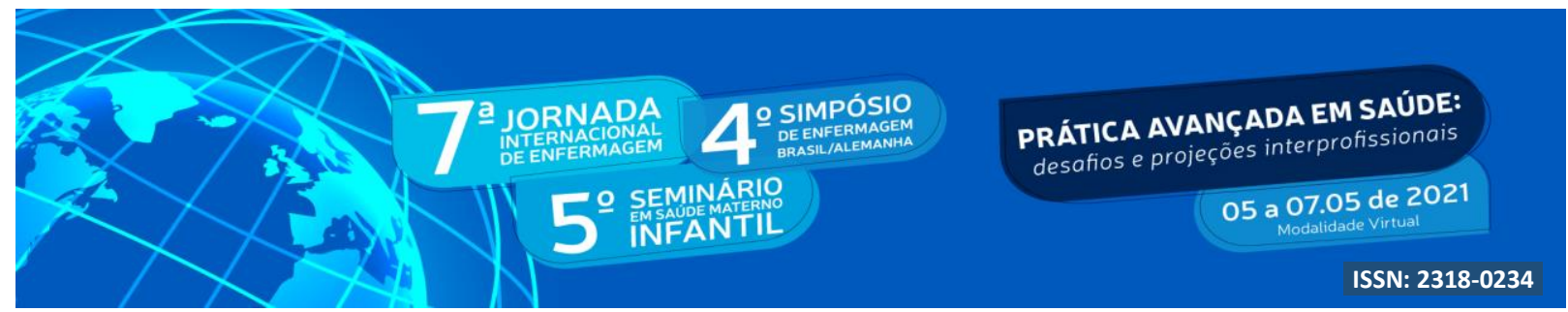

F.N.P. Atendimento de gestantes na atenção primária a saúde pela Enfermagem durante a pandemia do SARS-COV-2. Revista Nursing, São Paulo, v.23, n.269, p.4723-4726, 2020.

OLIVEIRA, T. F. D; CASTRO, J. M. D; COSTA, W. J. T. Principais características do covid-19: Revisão narrativa. Revista Artigos.com, Minas Gerais, v. 25, p. 1-9, 2021. Disponível em: <https://acervomais.com.br/index.php/artigos/article/view/4252/3976>. Acesso em: 11 mar. 2021.

PEAHL, A. F.; SMITH, R. D.; MONIZ, M. H. Redesenho da assistência pré-natal: criando modelos flexíveis de assistência à maternidade por meio da assistência virtual. American Journal of Obstetrics and Gynecology, v.223, n.3, 2020.

SOUTO, S. P. D; ALBUQUERQUE, R.S.D; PRATA, A. P. O medo do parto em tempos de pandemiade novo coronavírus. Revista Brasileira de Enfermagem, Brasília, v. 73, n. 2, p. 17, nov./ 2020. Diponível em: <https://www.scielo.br/pdf/reben/v73s2/pt_0034-7167-reben73-s2-e20200551.pdf>. Acesso em: 15 mar. 2021.

SOUTO, X. M. COVID-19: Aspectos gerais e implicações globais. Recital: Revista de educação, ciência e tecnologia de Almenara, Minas Gerais, v. 2, n. 1, p. 13-36, abr. 2020. Disponível em: <https://www.researchgate.net/profile/Xenia-

Souto/publication/341909843_Covid19_aspectos_gerais_e_implicacoes_globais/links/5ed901 0592851c9c5e7bc5ae/Covid-19-aspectos-gerais-e-implicacoes-globais.pdf $>$. Acesso em: 11 mar. 2021.

SOUZA, M. T. D; SILVA, M. D. D; CARVALHO, R. Revisão Integrativa: o que é e como fazer? Einstein, São Paulo, v. 8, n. 1, p. 102-106, Jan/Mar. 2010. Disponível em: <https://www.scielo.br/scielo.php?pid=S1679-

$45082010000100102 \&$ script=sci_arttext\&tlng=pt $>$. Acesso em: 11 mar. 2021.

SOUZA, K. V.; SCHNECK, S.; PENA, E. D.; DUARTE, E. D.; ALVES, V. H. Direitos humanos das mulheres no parto frente à pandemia de Covid-19: o que fazer da enfermagem obstétrica. Revista Cogitare enfermagem, v.25, e73148, 2020.

SOUZA, R. R. K.; GUALDA, D. M. R. A experiência da mulher e de seu acompanhante no parto em uma maternidade. Texto Contexto Enfermagem, v. 24, n. 1, e4080014, 2016. Disponível em: <https://doi. org/10.1590/0104-0707201600004080014>. Acesso em 11 mar. 2021. 